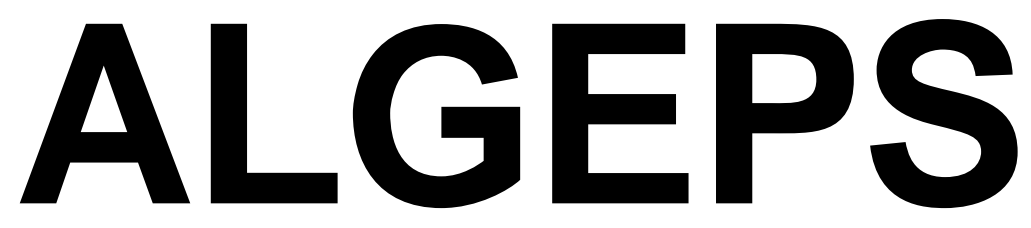

REVISTA DE GEOLOGIA, SĖRIE B no 638 - Juliol del 2013

ITINERARI GEOLÒGICO-MINERALÒGICO PER LES COMARQUES DE LA GARROTXA I D'OSONA: DES DE LES PRESES AL FAR, RUPIT, CANTONIGROS I A VIC

Josep M. Mata-Perelló i Joaquim Sanz Balagué 


\section{ITINERARI GEOLÒGICO-MINERALÒGICO PER LES COMARQUES DE LA GARROTXA I D'OSONA: DES DE LES PRESES AL FAR, RUPIT, CANTONIGROS I A VIC}

Per Josep M. Mata-Perelló i Joaquim Sanz Balaqué

\section{ADVERTIMENTS}

Es tracta d'una sortida efectuada fa uns set anys, la qual ha estat modificada, amb la introducció de noves observacions. Tot i així, gaudeix del mateix fil conductor que va tenir aleshores.

Per d'altra banda, és una clàssica sortida geològica $i$ mineralògica, estructurada en una sèrie de PARADES o ESTACIONS. En cada una d'elles es faran les observacions geològiques i/o mineralògiques pertinents que s'escaiguin.

En qualsevol cas, cal tenir sempre una cura molt especial de respecte a la natura, al llarg de tot el recorregut; de l'itinerari.

\section{BREU INTODUCCIÓ}

La totalitat del recorregut d'aquest itinerari discorrerà exclusivament per una sola de les unitats geològiques que constitueixen el subsòl del nostre país, concretament per la Depressió Geològica de l'Ebre.

Tot i així, s'iniciarà dintre dels sectors corresponents a la Serralada Transversal. Així, al llarg de tot el recorregut s'aniran trobant exclusivament afloraments dels materials cenozoics que reblen l'esmentada depressió.

Malgrat que el recorregut de l'itinerari discorrerà exclusivament per la Depressió Geològica de l'Ebre, al llarg del recorregut, s'efectuaran reconeixements a distància de les altres dues unitats que constitueixen el subsòl de Catalunya: tant dels Pirineus (situats al Nord dels sectors per on discorrerà el recorregut) com dels Catalànids (ubicat al SE).

Per d'altra banda, el present recorregut transitarà per dues comarques. Així, śniniciarà a la comarca de la Garrotxa (integrant de les Terres de Girona), per a finalitzar dintre de la comarca d'Osona (situada dintre de la denominada Catalunya Central). 


\section{OBJECTIUS GENERALS}

A través d'aquest itinerari geològic-mineralògic, s'intentaran d'aconseguir els següents objectius:

1.- Observació de la Zona volcànica de la Garrotxa (inclosa a la Serralada Transversal Catalana), de les seves estructures i dels seus materials. Així, aquesta observació la podrem fer fonamentalment des del Mirador de Xenacs.

2.- Observació de la Serralada Transversal Catalana (part integrant de la Depressió Geològica de l’Ebre) i en concret del sectors corresponents al Cabrerès. Això ho podrem fer des de diversos indrets del recorregut; especialment entre el mirador del Far i Rupit.

3.- Observació dels materials cenozoics que reblen la Depressió Geològica de l'Ebre (i tanmateix la Serralada Transversal Catalana), entre les Preses i el final del recorregut, prop de Vic. Aquests materials es distribueixen entre les següents unitats biostratigràfiques: Formació Armàncies, Formació Beuda (amb nivells de guixos blanc i grisosos), Formació Banyoles, Formació Coubet (amb conglomerats, gresos i calcàries), Formació Bracons, Formació Bellmunt, Formació Folgueroles (amb gresos i microconglomerats grisos), Unitat del Puigsacalm Superior (amb conglomerats, gresos i calcolutites grises) i Unitat Vidrà Inferior (amb gresos i calcolutites grises).

4,- Observació, a distància de les estructures de la Zona d'Apilaments Antiformes del Freser (del Sistema Pirinenc), que veurem al Nord del recorregut, des del Mirador de Xenacs, al principi del recorregut.

5.- Observació, a distància dels materials paleozoics (del Cambro-Ordovicià al Permià), que constitueixen la Zona d'Apilaments Antiformes del Freser.

6.- Observació des del Mirador del Far, del contacte, entre l'esmentada Serralada Transversal, i la Serralada Prelitoral Catalana del Sistema Mediterrani. Aquest contacte es fa palès al Sud del Far, mirant a Sant Martí Sacalm.

7.- Des del mateix indret, observació dels relleus de la Serralada Prelitoral Catalana (en el seu sector corresponent a les Guilleries). Aquests relleus es situen al Sud del Far i de Sant Martí Sacalm.

8.- Observació, al llarg del recorregut dels diferents elements del Patrimoni Geològic i Miner, que es vagin trobant.

\section{ANTECEDENTS}

No tenim cap constància de l'existència de cap itinerari, que discorri íntegrament pels indrets on ho fa el present. Existeixen però, alguns antecedents com els següents: farem esment d'uns itineraris nostres, com: MATA-PERELLÓ (1996, 1999 i 2007). 
També farem esment dels treballs de DURÁN I GOLD (1990) i GASSIOT i RIERA (1981).

Pel que fa a les característiques generals de la geologia regional, farem esment de dos treballs: GUIMERÀ et altri (1992), i RIBA et altri (1976). I, pel que fa a la geologia de la zona per la qual discorre el recorregut de l'itinerari, farem esment dels següents treballs: ARAÑA et altri (1983), IGME (1994a i 1994b), MALLARACH (1968) MALLARACH i RIERA (1981).

També, pel que fa a les mineralitzacions situades a les comarques per les quals discorre l'itinerari, farem esment d'un treball nostre; concretament de: MATAPERELLÓ (1991).

Tots aquests treballs figuren relacionats, per ordre alfabètic a l'apartat dedicat a la BIBLIOGRAFIA.

\section{RECORREGUT DE L'ITINERARI}

L itinerari s'iniciarà al poble de les Preses, per tal de pujar fins al mirador de Xenacs, per on es farà una aturada. Després ens caldrà tornar a les Preses, per tal de continuar cap a Bas (tot anant per la carretera comarcal C - 63 (1'antiga C-152).

A continuació, l'itinerari s’adreçarà cap el Coll de Candreu (seguint ara per la carretera C-153), i des d'aquí cap al Mirador del Far, per una carretera local. En arribarhi es farà una nova aturada.

Tot seguit ens caldrà retornar a la carretera comarcal C - 153, per tal d'arribar cap a Rupit, per on es farà una nova aturada. Tot seguit el recorregut continuarà cap a Can Toni Gros, Santa Maria del Corcó i cap a Vic, per on finalitzarà, després de ferse diverses aturades. En aquests darrers recorreguts es transitarà sempre per la carretera C -153 , tret d'algunes filloles.

\section{DESCRIPCIÓ DE L'ITINERARI}

Com ja es habitual, aquest itinerari s'estructurarà en una sèrie d'estacions (parades o aturades). En cada una d'aquestes parades es faran descripcions geològiques o mineralògiques, segons s'escaigui. En cada cas s'indicarà el número del mapa topogràfic a escala 1:50.000 on es troba l'indret.

En aquest cas, el recorregut de l'itinerari passarà per part dels dos següients fulls: 257 (dit d’Olot), 294 (o de Manlleu), 295 (o de Banyoles) i 333 (o de Vic). En tots els casos, aquests fulls són del IGC (Instituto de Geografia y de Cartografia de España).

Així doncs, la descripció de les diferents aturades que constitueixen el recorregut de l'itinerari, és la següent: 
PARADA 1. MIRADOR DE XENACS (terme municipal de les Preses, comarca de la Garrotxa). (Full 295).

L'itinerari s'inicia a la sortida de la població de les Preses. A uns 500m, anant cap a Sant Esteve del Bas, es troba un camí (per la dreta de la carretera) que condueix cap al mirador de Xenacs. En un recorregut d'una mica més de $4 \mathrm{Km}$, per una pista en bon estat, s'arriba a l'Àrea de Xenacs. Després, per un sender ben senyalitzat, cal anar a peu fins al mirador.

Tot aquest recorregut, des de les Preses fins al mirador de Xenacs, es realitza entre els materials terciaris de l'Eocè, constituïts per nivells de gresos, margues i calcàries, els quals cabussen clarament cap a l'Oest. Aquests materials pertanyen als primers trams del recorregut a la Formació Puigsacalm; mentre que els trams més alts corresponen a la Formació Bellmunt, tot i que aquests ocupen una posició estratigràfica inferior en relació als anteriors.

Tanmateix, des d'aquest indret, es fa ben palesa la Serralada Transversal Catalana, amb el Puigsacalm; així com de diversos indrets del Sistema Pirinenc, fent-se palesos molts sectors de la seva Zona Axial, com el Canigó i el Costabona, entre altres indrets. Igualment es fan palesos molts sectors corresponents als Pirineus Meridional, com el Massís del Montgrí.

PARADA 2. ENTRADA A JOANETES, (Joanetes, terme de la Vall d'En Bas, comarca de la Garrotxa). (Full 294).

Després de realitzar la parada anterior, ens caldrà baixar de nou cap al poble de les Preses . En arribar-hi, ens caldrà seguir per la carretera C- 63 (l'antiga C - 152). Per aquesta carretera, en arribar al veïnat de Joanetes (de la Vall d'En Bas), podem fer una nova aturada, després de recórrer uns $10 \mathrm{Km}$ des del Mirador de Xenacs.

Tot aquest recorregut, des de la parada anterior fins a l'indret de l'aturada, es van trobant afloraments dels materials terciaris de l'Eocè, constituïts per nivells de gresos, margues i calcàries, els quals cabussen clarament cap a l’Oest.

Des d'aquest indret, tot mirant cap al NW es pot gaudir de l'interessant relleu del Puigsacalm, situat al Cabreres. Es situa entre afloraments cenozoics, els quals formen un interessants relieves en cuesta.

PARADA 3. MIRADOR DEL FAR (terme municipal de Susqueda, comarca de la Selva). (Full 295).

Des de la parada anterior, cal continuar per la carretera C - 63 (l'antiga C - 152), anant sempre cap a ponent. Més endavant trobarem la cruïlla d'aquesta carretera amb la C - 153, per la qual ens caldrà continuar el recorregut, arribant al Coll de Candreu. I, tot seguit, des d'aquest punt s'anirà fins al Santuari del Far, per una carretera local. En arribar al Santuari, caldrà arribar fins al Mirador del Far. En aquest indret farem una nova aturada, després de recórrer uns $20 \mathrm{Km}$ des de l'anterior. 
El recorregut, des de la parada anterior, es realitza sempre entre els materials terciaris eocènics de la Serralada Transversal Catalana. Així, des del Coll de Candreu fins al Far es van tallant els nivells de margues grises i els de calcàries nummulítiques, que constitueixen el cingle del Far. FOTOGRAFIA 1.

Des d'aquest indret es pot gaudir d'una bona observació de la discordança entre els materials terciaris de la Serralada Transversal Catalana (que constitueixen els relleus del Far), i els paleozoics (i triàsics) de la Serralada Prelitoral Catalana, situats per de sota del mirador de Far, a Sant Martí Sacalm.

Igualment, es pot observar la "calma" triàsica de Sant Martí Sacalm, desenvolupada amb els materials d'aquest període cobrint als paleozoics, dintre de la Serralada Prelitoral Catalana.

Tanmateix, es poden observar els relleus "en cuesta" dels materials eocènics de la Serralada Transversal Catalana, entre Rupit, Sant Joan de Fàbregues i el Far.

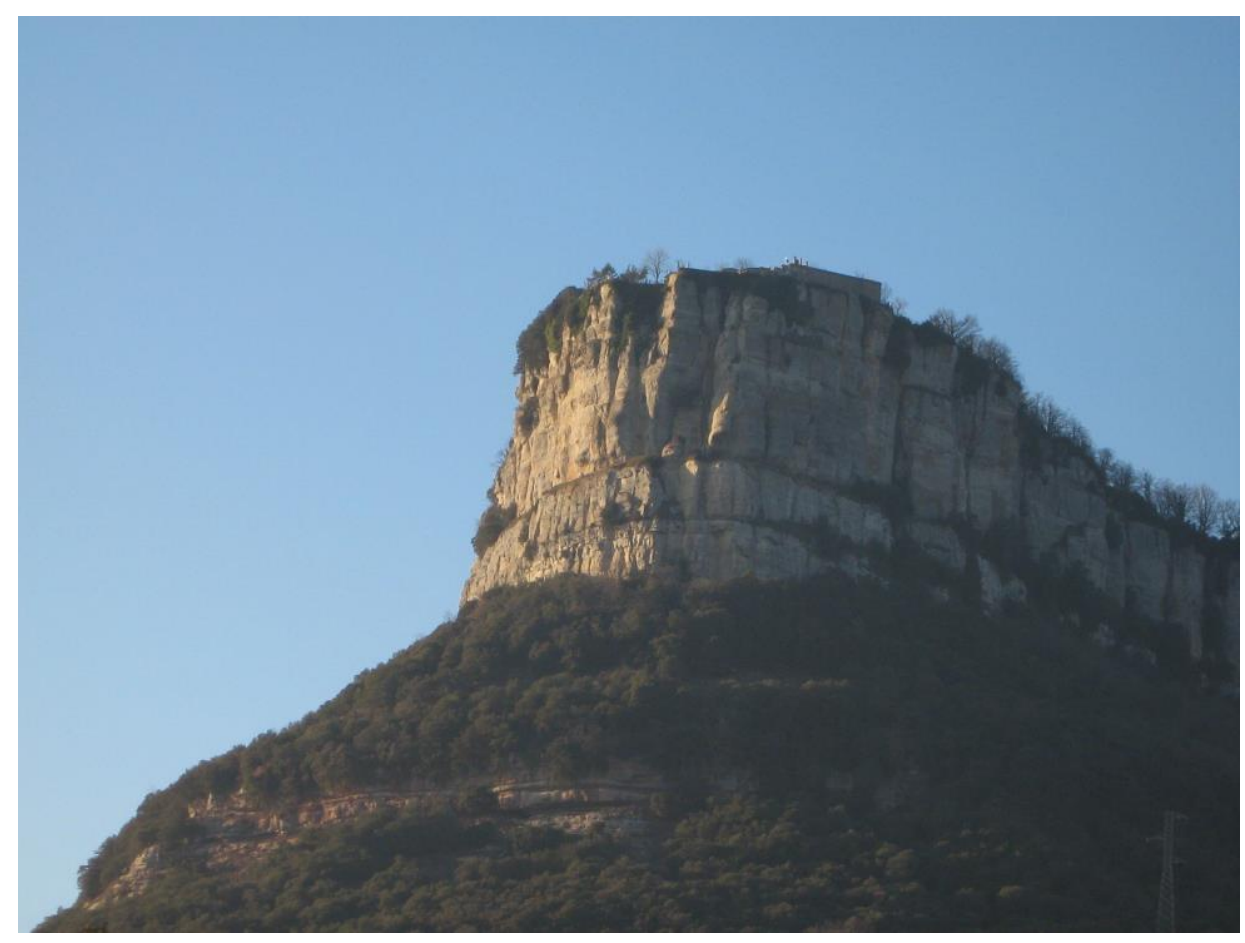

FOTOGRAFÍA 1. El Far, des de Sant Martí Sacalm

PARADA 4. LES CINGLES DE RUPIT, (terme municipal de Rupit, comarca d’Osona). (Full 294).

Després de realitzar la parada anterior, cal retornar cap a la carretera C-153, per tal de continuar cap a ponent. Així, en arribar al Coll de Cendreu, ens caldrà continuar cap a la població de Rupit. En arribar-hi, ens caldrà buscar un lloc proper a les Cingles de Rupit, per tal de fer una nova aturada, dintre del recorregut del present itinerari. Així, haurem recorregut uns $13 \mathrm{Km}$ més. 
En aquest recorregut, haurem trobat afloraments dels materials esmentats a les aturades anteriors. Aquets materials, de tonalitats eminentment grises, pel seu origen marí, són les apareixen a l'indret de la present aturada.

En aquest lloc, aquests materials formen part d'una interesant cinglera. Els materials que la formen es superposen sobre els terrenys triàsics i paleozoics de la Serralada Prelitoral Catalana. Aquests materials es troben al fons de la vall, als embassaments de Sau i Susqueda, visibles des de l’indret de l'aturada.

Entre els materials cenozoics de Depressió Geològica de l'Ebre (on ara som), es fan palesos uns nivells calcolutites i sorrencs, de tonalitats grisenques. Aquests materials pertanyen a la Formació Puigsacalm. Per sota d'aquests, es fan palesos uns afloraments rogencs (de caràcter eminentment detrític, sorrenc), que pertanyen a la Formació Vilanova de Sau.

\section{PARADA 5 - CONDICIONAL. VOLTANTS DE CANTONIGROS, (terme municipal de Santa Maria del Corcó, comarca d'Osona). (Full 294).}

Després de realitzar la parada anterior, cal retornar cap a la carretera $C-153$, per tal de continuar el recorregut cap a ponent. Més endavant, en arribar al trencall de Cantonigros, podem fer una nova aturada. Així, haurem recorregut uns $5 \mathrm{Km}$ més.

En aquest recorregut, haurem trobat els materials esmentats a les darreres aturades, que pertanyen fonamentalment a la Formació Puigsacalm, situant-nos dintre de la Depressió Geològica de l'Ebre. Tot $i$ així, ara els materials que apareixen en aquest indret són els de la Formació Igualada, amb afloraments de calcolutites gris blavoses. Entre aquests materials es troben cristal-litzacions de CALCITA $i$ de CELESTINA, tot reblint pistes fòssils

PARADA 6. LES CINGLES DE TAVERTET, (terme municipal de Tavertet, comarca d'Osona). (Full 333).

Després de realitzar la parada anterior, cal de nou continuar el recorregut cap a ponent per la carretera C - 153. Així, aviat arribarem a Santa Maria del Corcó. Aquí ens caldrà iniciar una fillola (d'uns $9 \mathrm{Km}$ ) amb la intenció d'arribar a les immediacions de Tavertet. En arribar-hi, podem fer una nova aturada, a uns $18 \mathrm{Km}$ de l'anterior.

Com als recorreguts anteriors, en aquest tram, hem continuat trobant afloraments dels materials que reblen la Depressió Geològica de l'Ebre, on estem ara situats. Aquests materials (per aquests indrets) són eminentment marins. Així ens hem trobat les calcolutites grisenques que formen part de de Formació Puigsacalm, que ja hem anat trobant en bona part del recorregut.

Ara, en arribar a les immediacions de Tavertet, haurem trobat uns afloraments de les denominades calcàries de Tavertet. Es tracta de calcaries de l'Eocè molt fossilíferes, fonamentalment de nummulites. 
Aquests nivells carbonatats formen un espectacular cingle, sobre el que s'assenta la població de Tavertet. Des d'aquest indret es pot observar la cinglera, que s'enlaira sobre la vall del riu Ter.

\section{PARADA 7. ESTACIÓ DE SERVEI DE VIC, SOBRE LA CARRTERA C - 25, (terme municipal de Gurb, comarca d'Osona). (Full 333).}

Després de realitzar la parada anterior, cal retornar cap a Santa Maria del Corcó, per tal de continuar cap a ponent per la carretera C-153. Així, aviat s'arribarà a Roda de Ter i més endavant a la carretera $\mathrm{C}-25$ (l’Eix Transversal), que circumval·la la població de Vic, fins entrar a l'Autovia de Ripoll. N trobar-la cal seguir per aquesta, anant cap el Sud, fins tornar a trobar 1’Eix Transversal. En arribar a 1'Estació de Servei, cal fer una nova aturada. Així, haurem recorregut uns 20 Km més.

La totalitat d'aquest tram l'haurem fet per la Depressió Geològica de l'Ebre. Així, haurem trobat afloraments dels materials cenozoics que la constitueixen. Així, en aquest indret afloren uns nivells de calcolutites de tonalitats gris - blavoses, de 1'Eocè, que pertanyen a la Formació Igualada. Precisament, aquests materials apareixen per arreu pels voltants de Vic, denominant-se molt sovint com a "margues de Vic".

\section{EN AQUEST LLOC FINALITZA EL PRESENT ITINERARI.}

\section{BIBLIOGRAFIA}

ARAÑA, S. et altri (1983).- El volcanismo neógeno-cuaternario de Catalunya: caracteres estructurales, petrográficos y geodinámicos. Acta Geológica Hispánica, 18 (1), pp. 1-17, Barcelona.

DURAN, H. i GOLD, E. (1990).- Itinerario por el Paleozoico de les Guilleries. Inédito. Barcelona

GASSIOT, X. i RIERA, M. (1981).- Itinerari per la Zona Volcànica de Catalunya. Pub. $I C E-U A B, 36$ pàgines. Barcelona.

GUIMERÀ, J. et altri (1992).- Geologia (II), Història Natural dels Països Catalans, Vol. 2, 547 pag. Enciclopèdia catalana, S.A., Barcelona.

IGME (1994a).- Mapa Geológico de España a escala 1:50.000, Segunda série, Primera edición. Hoja y memória $\mathrm{n}^{\mathrm{o}} 256$ (Ripoll). Ins. Geominero y Tecnológico de España. Ministerio de Indústria y Energia. Madrid.

IGME (1994b).- Mapa Geológico de España a escala 1:50.000, Segunda série, Primera edición. Hoja y memória $\mathrm{n}^{\circ} 257$ (Olot). Ins. Geominero y Tecnológico de España. Ministerio de Indústria y Energia. Madrid. 
MALLARACH, J. M. (1968).- Carta Geològica de la Regió Volcànica d’Olot. Edit.. Ajuntament d'Olot. Olot.

MALLARACH, J.M. i RIERA, M, (1981).- Els volcans olotins i el seu paisatge. Edit. Serpa. Barcelona.

MATA-PERELLÓ, J.M. (1991).- Els Minerals de Catalunya. Arxius de la Secció de Ciències, t. XCIII. Institut d'Estudis Catalans. Barcelona.

MATA-PERELLÓ, J.M. (1996).- Apunts per a un itinerari geològico - mineralògic per les comarques del Ripollès i de la Garrotxa: des de Campdevànol a Santa Pau, i a Sant Joan de les Fonts. Inèdit. 10 pàgines. Manresa

MATA-PERELLÓ, J.M. (1999).- Itinerari geològic - mineralògic per les comarques de la Garrotxa i de la Selva: des de les Preses a Sant Julià del Llor. Inèdit. 10 pàgines. Manresa

MATA-PERELLÓ, J.M. (2007).- Recorregut geològic i miner per les comarques de la Garrotxa i del Ripollès: des del Coll de Bracons a les Preses, Olot i a Sant Joan de les Abadesses. Inèdit. 10 pàgines. Manresa

RIBA ARDERIU, O. Et altri. (1976).- Geografia Física dels Països Catalans. Edit Ketres. Barcelona. 